\title{
Early Weight Bearing of Calcaneal Fractures Treated by Intraoperative 3D-Fluoroscopy and Locked-Screw Plate Fixation
}

\author{
B. Kienast ${ }^{*}, 1$, J. Gille ${ }^{2}$, C. Queitsch ${ }^{1}$, M.M. Kaiser ${ }^{2}$, R. Thietje ${ }^{1}$, C. Juergens ${ }^{2}$ and A.P. Schulz ${ }^{2}$ \\ ${ }^{I}$ Department of Traumatology, Orthopaedics and Sports Medicine, BG Trauma Center Hamburg, Germany \\ ${ }^{2}$ Department of Traumatology, Orthopaedics \& Reconstructive Surgery, University of Schleswig-Holstein, Campus \\ Luebeck, Germany
}

\begin{abstract}
Operative therapy of intraarticular fractures of the calcaneus is an established surgical standard. The aim is an accurate reduction of the fracture with reconstruction of Boehler's angle, length, axis and subtalar joint surface. Intraoperative 3D-fluoroscopy with the Siremobil Iso-C $3 \mathrm{D}^{\circledR}$ mobile $\mathrm{C}$-arm system is a valuable assistant for accurate reconstruction of these anatomical structures. Remaining incongruities can be recognized and corrected intraoperatively. The achieved reduction can be fixed by the advantages of an internal fixator (locked-screw plate interface). In the period of October 2002 until April 2007 we operated 136 patients with intraarticular fractures of the calcaneus by means of anatomical reduction, and internal plate fixator under intraoperative control of 3D-fluoroscopy. All patients were supplied with an orthesis after the operation which allowed weight bearing of $10 \mathrm{~kg}$ for 12 weeks for the patients operated between October 2002 and October 2004 (Group A). Transient local osteoporosis was observed in all X-Rays at follow-up after an average of 8,6 months. Therefore we changed our postoperative treatment plan for the patients operated between November 2004 and April 2007 (Group B). Weight bearing started with $20 \mathrm{KG}$ after 6 weeks, was increased to $40 \mathrm{KG}$ after 8 weeks and full weight bearing was allowed after 10 weeks for these patients. In no case a secondary dislocation of the fracture was seen. No bone graft was used. At follow up the average American Foot and Ankle Society Score (AOFAS) were 81 for Group A, compared to 84 for Group B, treated with earlier weight bearing. Autologous bone graft was not necessary even if weight bearing was started after a period of six weeks postoperatively. The combination of 3Dfluoroscopy with locked internal fixation showed promising results. If the rate of patients developing subtalar arthrosis will decrease by this management will have to be shown in long term follow up.
\end{abstract}

Keywords: Computer-assisted surgery, early weight bearing, calcaneal fracture, locked plate.

\section{INTRODUCTION}

In most cases intraarticular calcaneal fractures are caused by a high-energy axial force, like a fall from greater height [1]. The investigations of Essex-Lopresti 1951 [2] showed that depending upon accident mechanism, two main types of fracture occur: The "joint depression" and the "tongue type" fracture. More complex fractures can be interpreted with the help of computed tomography (CT-scan), often with the aid of 3D reconstruction [3]. Description of these complex injuries is aided by the classification described by Sanders [4]. According to Zwipp et al. [5] in 58\% the calcaneus is divided into 5 main fragments: sustentacular fragment, tuberositas fragment, posterior subtalar fragment, anterior process fragment and the anterior subtalar fragment. Comparison of surgical with conservative therapy for calcaneal fractures some studies showed superior results for the surgical treatment of intraarticular fractures. Especially in those fractures treated operatively, the overall clinical result was better when an anatomic reduction of the subtalar joint was achieved. Good results are achieved if the stable anatomical reduction of the posterior facet is possible [6-14]. However, it is not always possible to get a satisfactory

*Address correspondence to this author at the BG Trauma Center Hamburg, Bergedorfer Strasse 10, D-21033 Hamburg, Germany; Tel: +49-40-7306-0; Fax:+49-40-7306-3704; E-mail: b.kienast@buk-hamburg.de stability for the screws in multi-fragment fractures [15-18]. Though some studies showed a clear increase in stability of the osteosynthesis gained by an angular stable (locked) screw plate connection $[19,20]$, others did not verify these results [21]. So far, only little is published about the experiences and advantages when using an internal fixator for the stabilisation of intraarticular fractures [22, 23]. Subtalar incongruity over $1 \mathrm{~mm}$ can lead to early post traumatic arthrosis of the subtalar joint [24, 25]. Conventional 2-D fluoroscopy does not enable assessment of small incongruities intraoperatively. The use of intraoperative 3D-fluoroscopy enables visualisation of bone structures three-dimensionally and thereby recognition and correction of remaining incongruities [3, 26-31].

Different questions were investigated:

1. The value of intraoperative 3D-fluoroscopy to recognise insufficient reduction.

2. The value of a locked internal fixation to avoid secondary displacement.

3. The value of early weight bearing to avoid local osteoporosis and pain.

\section{MATERIALS AND METHODS}

\section{Patients}

Study design was retrospective in a prospective cohort. 


\section{Inclusion Criteria}

Included in this study were all patients that fulfilled our department's general criteria for surgical therapy of calcaneal fractures: Deformation of the calcaneus, the flattening of the foot (Boehler's angle), the intraarticular fracture type and the shortening or broadening of the hindfoot.

\section{Exclusion Criteria}

Contraindications were general or local contraindications to surgery in general, a biological age of more than 60 years, peripheral vascular disease and patients who might have been unwilling or unable to follow the postoperative regime. For some or all of these reasons 34 patients had to be excluded.

In the period from October 2002 until April 2007 we treated 136 patients with intraarticular calcaneal fractures with an internal fixator and intraoperative 3D-fluoroscopy. We operated 112 males and 24 females with an average age of 46.1 years (19-62 years). In 64 cases the right foot was involved.

The most frequent cause of accident was a fall $(n=104)$ from an average height of up to $3 \mathrm{~m}$. Traffic accidents were seen in 16 cases and other accidents in 16 cases. According to the classification by Essex-Lopresti, predominantly joint depression type fractures occurred $(n=124)$, with 12 cases of tongue type fractures. After routine preoperative CT scan, a classification according to Sanders was carried out [4]: 38 fractures were type II, 76 fractures type III and 22 were classified type IV. In 22 cases with calcaneal fractures, additional injuries were also diagnosed, 8 patients had suffered fractures of the spinal column.

Surgical treatment of the fractures took place once soft tissue conditions allowed. This was possible after an average of 7,2 days (5 to 11). In all cases a 3D-fluoroscopy was performed after reduction and temporary fixation of the fracture. Postoperatively radiographs were taken; we did not regularly perform CT scan postoperatively. All patients were supplied with an orthesis after the operation. Weight bearing of $10 \mathrm{~kg}$ for the period of 12 weeks was allowed for the patients operated from October 2002 until October 2004. Partial weight bearing was trained by a physiotherapist using a scale. Due to local osteoporosis observed in all X-Rays at follow-up, we changed our postoperative treatment plan for the patients operated between November 2004 and April 2007. Weight bearing started with $20 \mathrm{KG}$ after 6 weeks, and was increased to $40 \mathrm{KG}$ after 8 weeks for these patients. Full weight bearing was allowed after 10 weeks. With the orthesis no crutches were needed. All patients had pre- and postoperative X-Rays, so the change of the Boehler's angle and the length of the hindfoot could be measured exactly.

Clinical follow-up examination was performed on average 8.6 months postoperative (6-12 months). All followup examinations were performed by a specialised orthopaedic trauma Surgeon.

\section{Approach and Reduction}

Patients were positioned laterally on an operating table with a radiolucent carbon part. An extended lateral approach was performed. The approach was developed as a full- thickness flap. The lateral cortical fragment (bulge fragment) was then hinged away. Subsequently, a good view into the subtalar joint was obtained. The soft tissue flap was held back by titanium K-wires, which had been inserted into the talus and bent. Titanium K-wires were left in situ during Iso C-3D scanning. Use of the joy-stick technique with a Schanz-screw placed through the tuber calcanei achieves reduction and in particular the length and axis is regained.

The individually reduced bone fragments were fixed temporarily with titanium K-wires, which were inserted through the sole (Fig. 1).

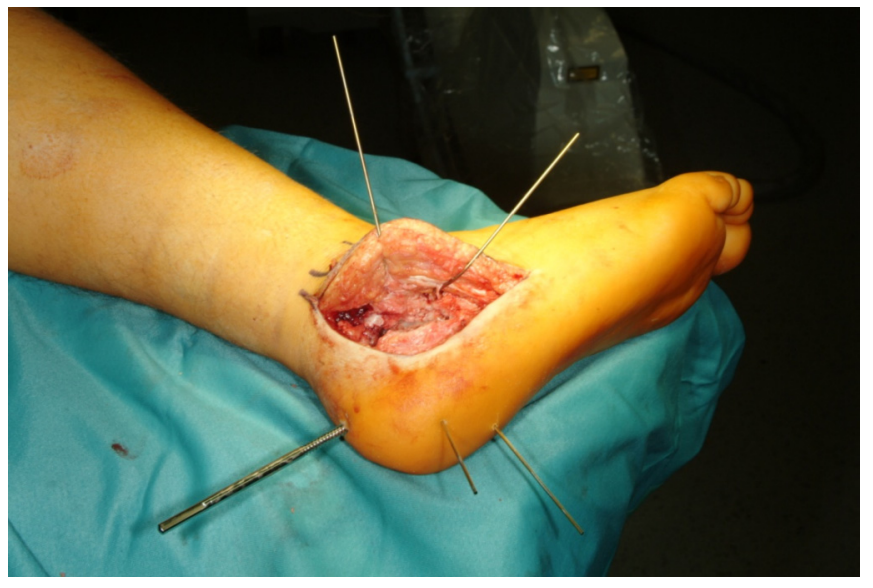

Fig. (1). The provisional reduction fixed with titanium K-wires.

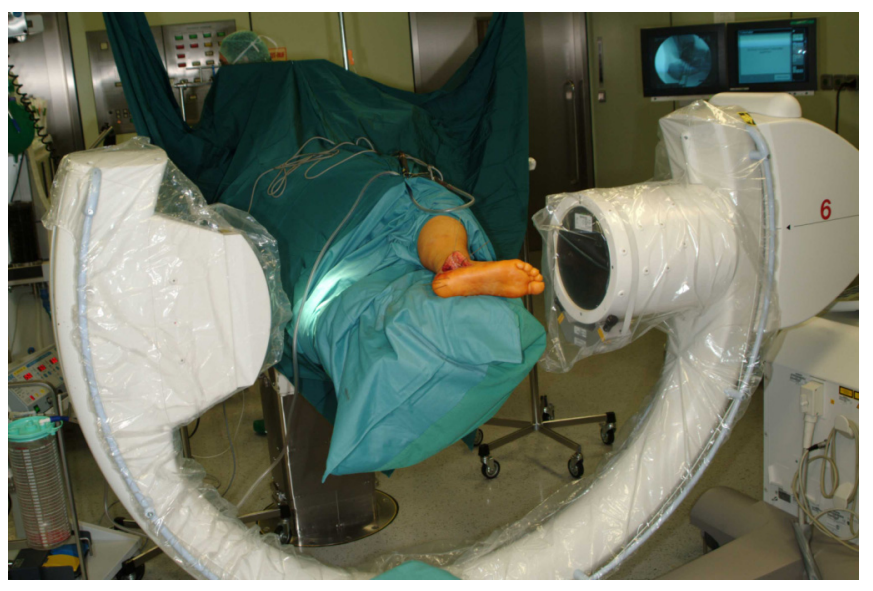

Fig. (2). The achieved reduction is being controlled intraoperatively by 3D-fluoroscopy (Siremobil ISO C 3D).

Siremobil ISO C 3D (Siemens Medical Solutions, Germany), a standard C-arm fluoroscopy coupled with a motor control for orbital motion and a computer-system for 3D reconstruction enables intraoperative 3D-fluoroscopy control (Fig. 2). The motorised C-arm provides fluoroscopic images during a single motor-driven orbital sweep of $190^{\circ}$. A defined number of images (50 or 100) are acquired at fixed angular increments. The system simultaneously produces a high-resolution, isotropic data volume from the individual images. Data can be processed by the surgeon intra-operatively, providing a multi-planar 2D reconstruction similar to the type provided with CT. Three different angles are then displayed on a computer screen: (semi)coronar, sagittal and axial. On the reconstructions, the surgeon can visualise any remaining incongruence within the joint. 
Any remaining subtalar incongruity over $1 \mathrm{~mm}$ can be seen and immediately improved. Subsequently an internal titanium-fixator is modelled to the calcaneus and fixed with appropriate locked screws (Fig. 3).

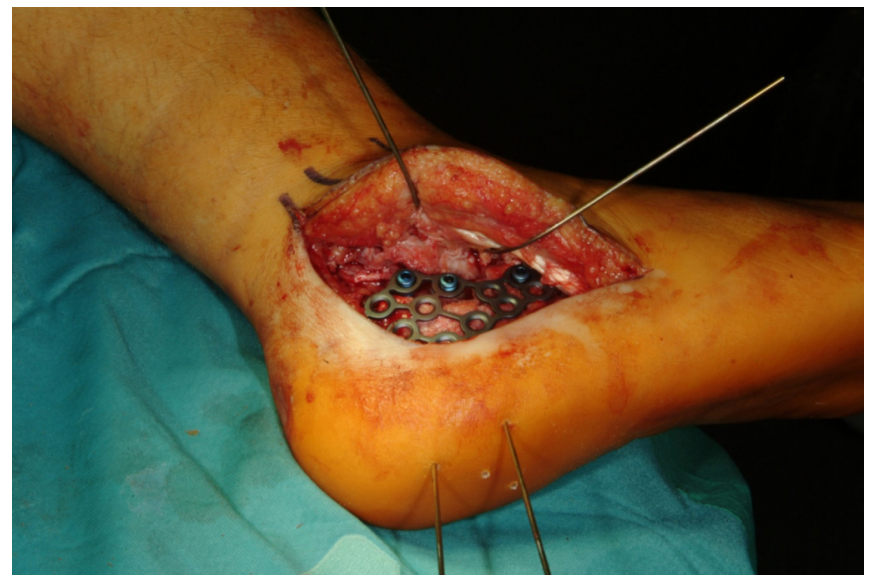

Fig. (3). Fixation of the plate with locked screws.

Particular care is taken to fix the central fragment (posterior subtalar fragment) in a good and stable position.

We do not regularly perform another 3D-fluoroscopy after internal fixation. Only if the surgeon is unsure about intraarticular position of screws another 3D-fluoroscopy is performed.

\section{Implant}

The implant used was a multi-directional locked-screw internal plate fixator $\operatorname{VariAx}^{\odot}$ Calcaneus Mesh Plate, STRYKER $^{\circledR}$, Schönkirchen/Germany (Fig. 4), in some of the early cases we used the Tifix $^{\circ}$-Calcaneus-Plate, LITOS, Hamburg/Germany, which is identical in construction. The plate is made of pure titanium with locking holes for titanium screws which can be fixed in different angles. Multidirectional interlocking is possible because the plate itself does not have a thread but a lip. By inserting a screw with an extra thread in the head, the screw cuts its own thread into the plate at an angle determined by the surgeon. Because of an increasing thread diameter, it locks in this position. The reshaping process is possible because plate and screw are made of titanium of different hardness-grade (plate in the softer grade 1 titanium, the screw in grade 4).

\section{RESULTS}

The median theatre time was 68 minutes $(50-112$ minutes) including 3D-fluoroscopy. In 57 cases (42\%) a remaining incongruity of more than $1 \mathrm{~mm}$ was detected with the intraoperative 3D-fluoroscopy. In all these cases reduction and 3D-scan was repeated. Boehler's angle and calcaneal length was measured on postoperative lateral native X-Ray films. The Boehler's angle could be raised on average by 19 degrees $\left(10^{\circ}\right.$ to $\left.24^{\circ}\right)$. The shortening of the hindfoot was improved by an average of 12 picture millimetres.

In 9 cases another 3D-fluoroscopy was performed after locked plate osteosynthesis. In one case two screws required repositioning (Fig. 5).

An autologous bone graft was not required in any case of this study. A secondary loss of correction was not seen in both Groups of the study. The achieved reduction could be fixed by the implant until full weight bearing was reached (Table 1) in all cases.

Table 1. Results after Surgical Treatment

\begin{tabular}{|c|c|c|c|}
\hline & Before & $\begin{array}{c}\text { After } \\
\text { Operation }\end{array}$ & Improvement \\
\hline \hline Boehler's angle $\left(^{\circ}\right)$ & $0(-10$ to 5) & $19(16-32)$ & 19 \\
\hline Hindfoot length (mm) & $24(18-33)$ & $36(30-42)$ & 12 \\
\hline
\end{tabular}

During postoperative treatment we detected $7(5,1 \%)$ superficial wound edge necroses, which all healed completely with conservative management. One haematoma had to be revised and subsequently healed without any further problems.

One case developed a deep infection 20 days postoperatively. In this case the implant had to be promptly removed. Non weight bearing was necessary for a further 3 weeks. In this particular case the Boehler's angle and hindfoot length were salvaged but the patient developed early subtalar arthritis with ankylosis.

Until follow-up after an average of 8,6 months, in no case an arthrodesis was required. If the number of patients developing subtalar arthrosis with the need of arthrodesis will increase at long-term follow-up will have to be shown. At the follow up examination all patients had returned to work, or had been judged fit to work by their GP. Seven patients had to change their position within their company, all seven were builders and involved in heavy lifting and climbing ladders as part of their previous position. 66 patients were completely pain free at follow-up. Two
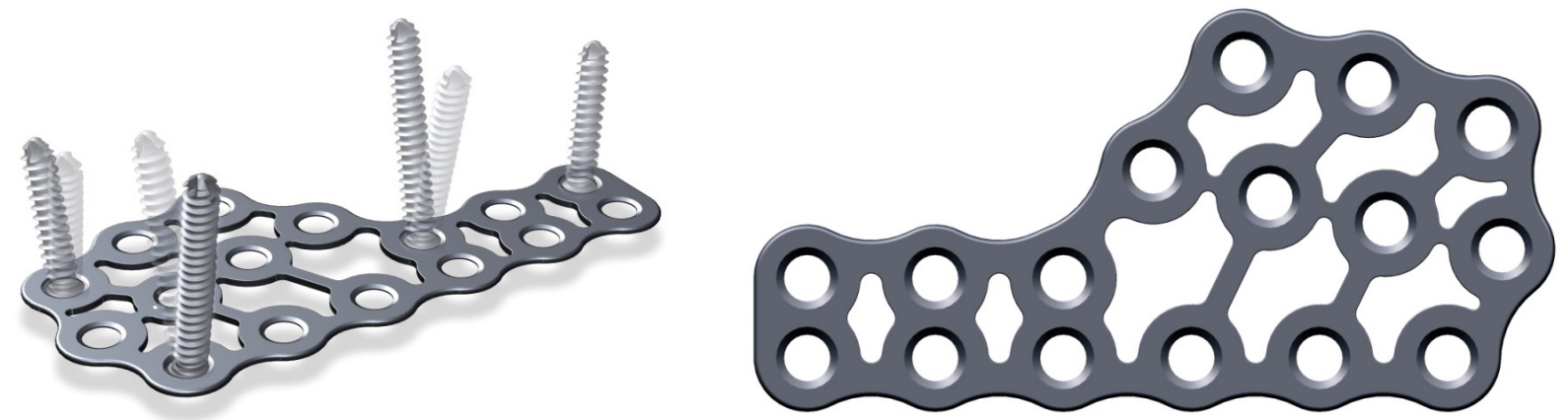

Fig. (4). Multi-directional internal plate fixator. 


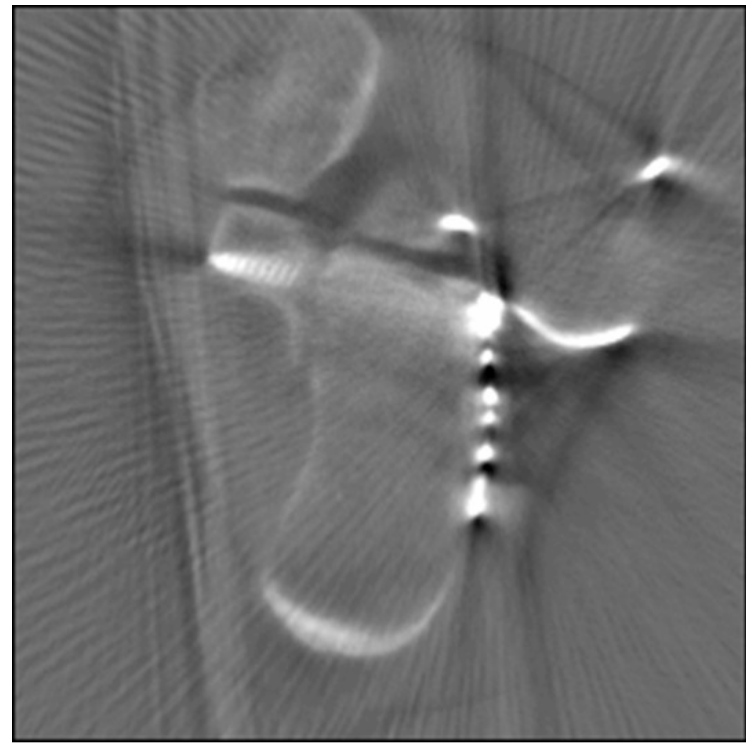

Fig. (5). Intraoperative 3D-fluoroscopy.

patients complained about constant pain. One of these patients had developed an early subtalar arthrosis after wound infection and early implant removal (Tables $\mathbf{2}$ and 3). More patients treated with early weight bearing (Group B) were pain free $(53 \%)$ compared to the patients treated with weight bearing after 12 weeks (Group A, 43\%). Overall 49\% of the patients were pain free, $42 \%$ complained pain after heavy work or sporting activities, $8 \%$ stated severe pain after moderate work/sporting activities and $2 \%$ were suffering from constant pain. At follow up X-Rays local osteoporosis appeared to be less severe in the patients of Group B. At follow up the average American Foot and Ankle Society Score (AOFAS, [32]) was 81 (49-88) for Group A, compared to $84(48-89)$ for Group B, treated with early weight bearing.

\section{DISCUSSION}

Although surgical treatment of displaced calcaneal fractures is an established surgical standard [5, 8, 33-35] it is not clear, if accurate anatomic reduction is of major importance [36]. Actual literature showed that fracture volume treated by an institution is an independent

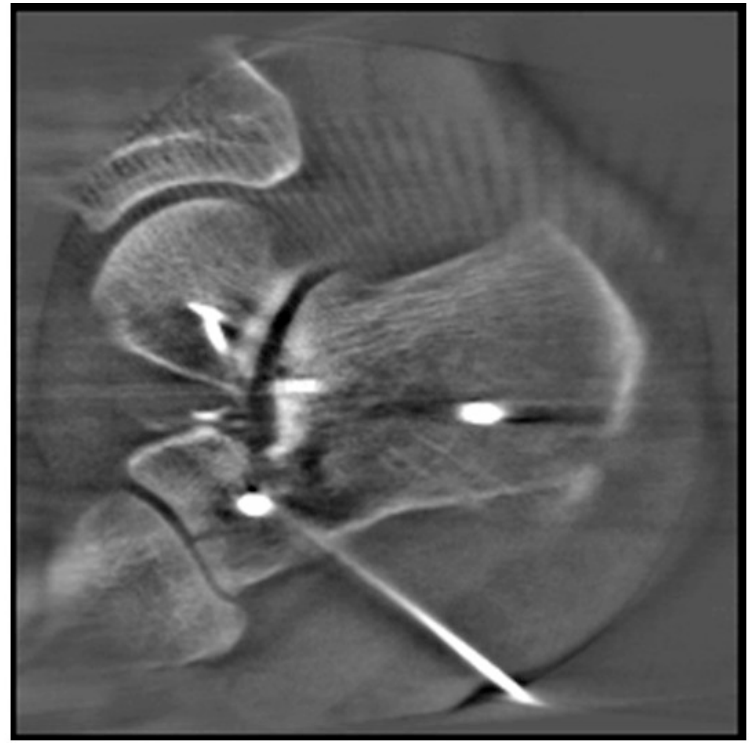

determinant for the postoperative infection rate and for the development of subtalar arthritis [37]. Infection rate in our study $(5,1 \%)$ is in accordance to the findings of the metaanalysis of Poeze et al. [37]. If a significant reduction of subtalar arthritis with the following need for arthrodesis could be obtained in our group treated with intraoperative 3D-fluoroscopy, angular stable implant and earlier weight bearing has to be shown in longer-term follow-up with inclusion of a control group. The restoration of the tension of the plantar fascia by reconstruction of Boehlers angle and hindfoot length is important for the biomechanics of the foot $[5,8,9,12]$. CT diagnostic provided improved understanding of calcaneal fractures and led to a clinically relevant classification of these injuries [4, 24, 38,39]. Thus a better surgical planning became possible. Anatomical and biomechanical studies refer to the important role of the posterior joint facet, which has to be stabilised to reconstruct the subtalar joint $[6,40,41]$. Only the accurate reduction with re-establishment of statics and function of the foot allows normal biomechanics [5, 35, 39, 40]. It is well-known, that already small subtalar incongruity of only $1 \mathrm{~mm}$ can lead to early arthritis of the corresponding joints [6, 42, 43]. Small incongruity cannot be properly assessed using

Table 2. Pain at Follow-Up Examination

Group A. (Operation Between Oct 2002 and Oct 2004, Weight Bearing Started after 12 Weeks)

\begin{tabular}{|c|c|c|c|c|}
\hline Pain at Follow-Up & No Pain & $\begin{array}{c}\text { Occasional/Mild Pain, After Heavy } \\
\text { Work/Sporting Activities }\end{array}$ & $\begin{array}{c}\text { Severe Pain, After Moderate } \\
\text { Work/Sporting Activities }\end{array}$ & Constant Pain \\
\hline \hline Patients & $25(43 \%)$ & $27(47 \%)$ & $5(9 \%)$ & $1(1 \%)$ \\
\hline
\end{tabular}

Table 3. Pain at Follow-Up Examination

Group B. (Operation Between Nov 2004 and April 2007, Weight Bearing Started after 6 Weeks)

\begin{tabular}{|c|c|c|c|}
\hline Pain at Follow-Up & No pain & $\begin{array}{c}\text { Occasional/Mild Pain, after Heavy } \\
\text { Work/Sporting Activities }\end{array}$ & $\begin{array}{c}\text { Severe Pain, after Moderate } \\
\text { Work/Sporting Activities }\end{array}$ \\
\hline \hline Patients & $41(53 \%)$ & $30(38 \%)$ & $6(8 \%)$ \\
\hline
\end{tabular}


conventional C-arm fluoroscopy [44]. In 57 cases we found a remaining displacement of more than $1 \mathrm{~mm}$. With intraoperative $3 \mathrm{D}$-fluoroscopy remaining incongruity can be recognized and corrected immediately [3, 27-29, 44]. Special plates have been invented to suit the needs for the treatment of calcaneal fractures (e.g. AO calcaneal plate, Galveston plate, low contact plate). The selected implant should be able to neutralize the forces resulting from the Achilles tendon and maintain reduction of the fragments until bony consolidation [30, 34, 39]. Due to our positive experience with the treatment of other fracture types with locked implants, we developed a thin titanium multi-directional angular stable internal fixator (Fig. 4) [23]. Because of the variety of holes each fracture can be treated individually. Especially the main fragment (posterior fragment) can be fixed safely. In our expertise-based impression this thin multidirectional angular stable plate design seems to facilitate wound healing, allows short operating times and can retain reduction without the need for bone grafts. To avoid severe postoperative osteoporosis, which often comes with pain during and after rehabilitation, we recommend weight bearing as early as possible.

\section{CONCLUSION}

Surgical treatment of calcaneal fractures using 3Dfluoroscopy intra-operatively provides the opportunity to recognize and correct remaining subtalar incongruity. Using 3D imaging improves the quality and safety of surgical treatment of calcaneal fractures and reduces the risk of revision surgery. With a multi-directional internal fixator it could be shown that in multi-fragment fractures the intraoperative reconstruction can be maintained until bony consolidation and secondary loss of correction can be avoided. Autologous bone graft seems no longer necessary even if weight bearing was started after a period of six weeks postoperatively. The combination of 3D-fluoroscopy with locked internal fixation could show promising results. Our short term outcome showed good functional results with a high percentage of patients returning to their previous occupation. If the number of patients developing subtalar arthrosis will decrease by this management will have to be shown in long term follow up. The study is limited by missing control groups comparing intraoperative 2D- and 3D-fluoroscopy and angular stable versus conventional plate fixation.

\section{REFERENCES}

[1] Stockenhuber K, Seggl W, Feichtinger G, Szyszkowitz R. Conservative and semiconservative treatment of calcaneus fractures. Orthopade 1991; 20(1): 43-54.

[2] Essex-Lopresti P. The mechanism, reduction technique, and results in fractures of the os calcis. Br J Surg 1952; 39(157): 395-419.

[3] Wich M, Spranger N, Ekkernkamp A. Intraoperative imaging with the ISO C(3D). Chirurg 2004; 75(10): 982-7.

[4] Sanders R, Fortin P, DiPasquale T, Walling A. Operative treatment in 120 displaced intraarticular calcaneal fractures: Results using a prognostic computed tomography scan classification. Clin Orthop Relat Res 1993; 290: 87-95.

[5] Zwipp H, Tscherne H, Thermann H, Weber T. Osteosynthesis of displaced intraarticular fractures of the calcaneus: Results in 123 cases. Clin Orthop Relat Res 1993; 290: 76-86.

[6] Jarvholm U, Korner L, Thoren O, Wiklund LM. Fractures of the calcaneus: A comparison of open and closed treatment. Acta Orthop Scand 1984; 55(6): 652-6.
[7] Benirschke SK, Sangeorzan BJ. Extensive intraarticular fractures of the foot. Surgical management of calcaneal fractures. Clin Orthop Relat Res 1993; 292: 128-34.

[8] Zwipp H, Tscherne H, Wulker N, Grote R. Intra-articular fracture of the calcaneus: Classification, assessment and surgical procedures. Unfallchirurg 1989; 92(3): 117-29.

[9] Bauer G, Kinzl L. The "low contact plate" for stabilizing the dislocated intra-articular calcaneus fractures. Chirurg 1996; 67(11): 1129-34.

[10] Bezes H, Massart P, Fourquet JP. Osteosynthesis of calcaneus impression fractures: Indication, technic and results in 120 cases. Unfallheilkunde 1984; 87(9): 363-8.

[11] Buckley RE, Meek RN. Comparison of open versus closed reduction of intraarticular calcaneal fractures: a matched cohort in workmen. J Orthop Trauma 1992; 6(2): 216-22.

[12] Kortmann HR, Wolter D, Bisgwa F, Meffert R. Treatment of calcaneus and mid-foot fractures using closed reposition and fixation with the Ilisarov fixator. Unfallchirurg 1992; 95(11): 541-6.

[13] O'Farrell DA, O'Byrne JM, McCabe JP, Stephens MM. Fractures of the os calcis: improved results with internal fixation. Injury 1993; 24(4): 263-5.

[14] Bajammal S, Tornetta P, 3rd, Sanders D, Bhandari M. Displaced intra-articular calcaneal fractures. J Orthop Trauma 2005; 19(5): $360-4$.

[15] Schildhauer TA, Bauer TW, Josten C, Muhr G. Open reduction and augmentation of internal fixation with an injectable skeletal cement for the treatment of complex calcaneal fractures. J Orthop Trauma 2000; 14(5): 309-17.

[16] Burdeaux BD, Jr. The medical approach for calcaneal fractures. Clin Orthop Relat Res 1993; 290: 96-107.

[17] Cohen M. Surgical management of the acute calcaneal joint depression fracture: The VAMC Miami experience. J Foot Ankle Surg 1996; 35(1): 2-12.

[18] Crosby LA, Fitzgibbons T. Intraarticular calcaneal fractures. Results of closed treatment. Clin Orthop Relat Res 1993; 290: 47-54.

[19] Stoffel K, Booth G, Rohrl SM, Kuster M. A comparison of conventional versus locking plates in intraarticular calcaneus fractures: A biomechanical study in human cadavers. Clin Biomech (Bristol, Avon) 2007; 22(1): 100-5.

[20] Richter M, Gosling T, Zech S, et al. A comparison of plates with and without locking screws in a calcaneal fracture model. Foot Ankle Int 2005; 26(4): 309-19.

[21] Redfern DJ, Oliveira ML, Campbell JT, Belkoff SM. A biomechanical comparison of locking and nonlocking plates for the fixation of calcaneal fractures. Foot Ankle Int 2006; 27(3): 196201.

[22] Johnson EE, Gebhardt JS. Surgical management of calcaneal fractures using bilateral incisions and minimal internal fixation. Clin Orthop Relat Res 1993; 290: 117-24.

[23] Kranz HW, Wolter D, Queitsch C, Reimers N. Operative treatment of intraarticular calcaneal fractures with a titanium internal fixator. Trauma und Berufskrankheit 1999; 1(4): 361-4.

[24] Zwipp H, Tscherne H, Wulker N. Osteosynthesis of dislocated intra-articular calcaneus fractures. Unfallchirurg 1988; 91(11): 50715.

[25] Hanson ST. Posttrauamtic malalignment of the hindfoot. Orthopäde 1991; 29: 95.

[26] Wendt $\mathrm{H}$. Calcaneus fracture treatment using the principle of extreme muscle relaxation. Hefte Unfallheilkd 1979; 133: 188-95.

[27] Euler E, Wirth S, Linsenmaier U, Mutschler W, Pfeifer KJ, Hebecker A. Comparative study of the quality of C-arm based 3D imaging of the talus. Unfallchirurg 2001; 104(9): 839-46.

[28] Gebhard F, Kinzl L, Arand M. Computer-assisted surgery. Unfallchirurg 2000; 103(8): 612-7.

[29] Kotsianos D, Rock C, Euler E, et al. 3-D Imaging with a mobile surgical image enhancement equipment (ISO-C-3D): Initial examples of fracture diagnosis of peripheral joints in comparison with spiral CT and conventional radiography. Unfallchirurg 2001; 104(9): 834-8.

[30] Rock C, Linsenmaier U, Brandl R, et al. Introduction of a new mobile $\mathrm{C}-\mathrm{arm} / \mathrm{CT}$ combination equipment (ISO-C-3D): Initial results of 3-D sectional imaging. Unfallchirurg 2001; 104(9): 82733. 
[31] Queitsch C, Schulz AP, Haustedt N, Fuchs S. Improved therapy of calcaneal fractures by intraoperative 3D-fluoroscopy and lockedscrew plate fixation. Eur J Trauma 2006; 32(5): 471-6.

[32] Kitaoka HB, Alexander IJ, Adelaar RS, Nunley JA, Myerson MS, Sanders M. Clinical rating systems for the ankle-hindfoot, midfoot, hallux, and lesser toes. Foot Ankle Int 1994; 15(7): 349-53.

[33] Bauer G, Mutschler W, Zenkl M, Heuchemer T. Operative therapy of intraarticular calcaneal fractures. Hefte Unfallchirurgie 1993; 230: 265-70.

[34] Wendl K, von Recum J, Wentzensen A, Grutzner PA. Iso-C(3D0assisted) navigated implantation of pedicle screws in thoracic lumbar vertebrae. Unfallchirurg 2003; 106(11): 907-13.

[35] Carr JB. Surgical treatment of the intra-articular calcaneus fracture. Orthop Clin North Am 1994; 25(4): 665-75.

[36] Swanson SA, Clare MP, Sanders RW. Management of intraarticular fractures of the calcaneus. Foot Ankle Clin 2008; 13(4): $659-78$.

[37] Poeze M, Verbruggen JP, Brink PR. The relationship between the outcome of operatively treated calcaneal fractures and institutional fracture load. A systematic review of the literature. J Bone Joint Surg Am 2008; 90(5): 1013-21.
[38] Melcher GA, Bereiter H, Lautenegger A, Rüedi T. Results after osteosynthesis of intraarticular calcaneal fractures. Aktuelle Chir 1989; 24: 62-7.

[39] Sanders R. Displaced intra-articular fractures of the calcaneus. J Bone Joint Surg Am 2000; 82(2): 225-50.

[40] Eastwood DM, Langkamer VG, Atkins RM. Intra-articular fractures of the calcaneum. Part II: Open reduction and internal fixation by the extended lateral transcalcaneal approach. J Bone Joint Surg Br 1993; 75(2): 189-95.

[41] Stephenson JR. Surgical treatment of displaced intraarticular fractures of the calcaneus: A combined lateral and medial approach. Clin Orthop Relat Res 1993; 290: 68-75.

[42] Leung KS, Lam TP, Poon KM. Operative treatment of displaced intra-articular glenoid fractures. Injury 1993; 24(5): 324-8.

[43] Paley D, Hall H. Intra-articular fractures of the calcaneus: A critical analysis of results and prognostic factors. J Bone Joint Surg Am 1993; 75(3): 342-54.

[44] Rubberdt A, Feil R, Stengel D, et al. The clinical use of the ISO$\mathrm{C}(3 \mathrm{D})$ imaging system in calcaneus fracture surgery. Unfallchirurg 2006; 109(2): 112-8.

(C) Kienast et al.; Licensee Bentham Open.

This is an open access article licensed under the terms of the Creative Commons Attribution Non-Commercial License (http://creativecommons.org/licenses/by-nc/ 3.0/) which permits unrestricted, non-commercial use, distribution and reproduction in any medium, provided the work is properly cited. 